\title{
Four-arm single docking full robotic surgery for low rectal cancer: technique standardization
}

\author{
Cirurgia robótica para o tratamento do câncer do reto distal: sistematização \\ técnica
}

TCBC José Reinan Ramos'; Eduardo Parra-Davila ${ }^{2}$

\begin{abstract}
The authors present the four-arm single docking full robotic surgery to treat low rectal cancer. The eight main operative steps are: 1 - patient positioning; 2-trocars set-up and robot docking; 3 - sigmoid colon, left colon and splenic flexure mobilization (lateral-to-medial approach); 4-Inferior mesenteric artery and vein ligation (medial-to-lateral approach); 5total mesorectum excision and preservation of hypogastric and pelvic autonomic nerves (sacral dissection, lateral dissection, pelvic dissection); 6- division of the rectum using an endo roticulator stapler for the laparoscopic performance of a doublestapled coloanal anastomosis (type I tumor); 7- intersphincteric resection, extraction of the specimen through the anus and lateral-to-end hand sewn coloanal anastomosis (type II tumor); 8-cylindric abdominoperineal resection, with transabdominal section of the levator muscles (type IV tumor). The techniques employed were safe and have presented low rates of complication and no mortality.
\end{abstract}

Key words: Rectal neoplasms. Treatment. Surgery. Techniques. Robotics.

\section{INTRODUCTION}

$\mathrm{T}$ he general consensus is still that the majority of adenocarcinomas of the rectum located in its distal portion ( $<5 \mathrm{~cm}$ from the anal verge) are to be treated by abdominoperineal resection (APR) of the rectum 1. However, with better knowledge of the importance of the circumferential resection margin, total mesorectal excision $(\mathrm{TME})^{2}$, currently joined by the routine use of neoadjuvant chemoradiotherapy $(\mathrm{QRT})^{3}$, new operative techniques with sphincter preservation have risen. The individualization of the best operation, which is facilitated by examination of pelvic magnetic resonance imaging (MRI) ${ }^{4}$, was advocated ${ }^{5}$ with the proposition of a classification divided into four tumor types (supra-anal, juxta-anal, intra-anal and transanal) and, respectively, four types of operations (ultra-low anterior resection, partial intersphincteric resection (IR), total IR and APR). Han et al. proposed the extra-elevator or cylindrical customization of abdominoperineal resection of the rectum, suggesting that the extent of resection be made in accordance with the invasion of the elevator muscles of the anus ${ }^{6}$.

Randomized ${ }^{7-9}$ and nonrandomized ${ }^{10-12}$ trials confirmed the benefits of laparoscopic operation in the treatment of rectal cancer. Nevertheless, due to the long learning curve and high conversion rate, the global impact of the use of this method is still small, especially in obese and male patients. It is estimated that only $10 \%$ of cases of colorectal cancer are currently treated by laparoscopy. The use of the robotics platform as a minimally invasive access has gained much interest in the surgical area of rectal cancer worldwide ${ }^{13,14}$. The robotic system enhances visualization, exposure and dissection of the noble structures in a narrow space such as the pelvic cavity.

The purpose of this publication is to present the full technical aspects of robotic techniques for: the ultralow anterior resection of the rectum with coloanal anastomosis by double stapling; the intersphincteric resection with manual coloanal anastomosis; the extraelevator or cylindrical abdominoperineal resection of the rectum in the modified lithotomy position.

\section{SURGICAL TECHNIQUE}

\section{1 - Starting position of the patient}

After general anesthesia, the patient is placed in modified lithotomy position (Lloyd-Davis) with arms along the trunk, and an oro or nasogastric catheter and a bladder catheter are inserted. The correct and safe patient position

1. Robotic Surgery Service, Hospital Samaritano, Rio de Janeiro, RJ, Brazil; 2. Medical Director for Colorectal Surgery, Florida Hospital Celebration Health, Orlando, USA.

This technical note has a video, available at www.cbc.org.br 
is facilitated by the use of Dan Allen leggings and the vacuum plaid (Gel bean bag).

\section{2 - Positioning of the trocars}

After the umbilical Veress needle puncture and instillation of $\mathrm{CO}_{2}$, the intra-abdominal pressure is maintained between $10-13 \mathrm{mmHg}$. A short $5-12 \mathrm{~mm}$ trocar is inserted on the right flank, where a $30^{\circ}$ laparoscope is used for inspection of the abdominal cavity and insertion of the four other trocars (three $8 \mathrm{~mm}$, robotic, permanent trocars and one $5-12 \mathrm{~mm}$ long disposable trocar for the camera) under internal vision. The robotic trocars are positioned at a distance of $8-10 \mathrm{~cm}$ from each other in a half moon shape (Figure 1). The patient in then repositioned to a $20-30^{\circ}$ steep Trendelenburg position and $1020^{\circ}$ to the right side to properly expose the promontorium, the bifurcation of the aorta and the inferior mesenteric vessels.

\section{3 - Positioning the robot and the tower}

The robot (da Vinci SI System) is positioned near the left lower limb at an angle of $30^{\circ}$. The robotic camera arm is connected to the long $12 \mathrm{~mm}$ trocar (3DHD camera with $30^{\circ}$ down scope) and the other three arms are connected to the $8 \mathrm{~mm}$ trocars, the arm 1 on the right trocar (monopolar scissors or hook), the arm 2 in the left medial trocar ( Cadiere fenestrated bipolar forceps) and the third arm in the left lateral trocar (long grasper forceps). The tower with the monitor is placed to the left of the patient in the best position to the auxiliary view (Figure 2).

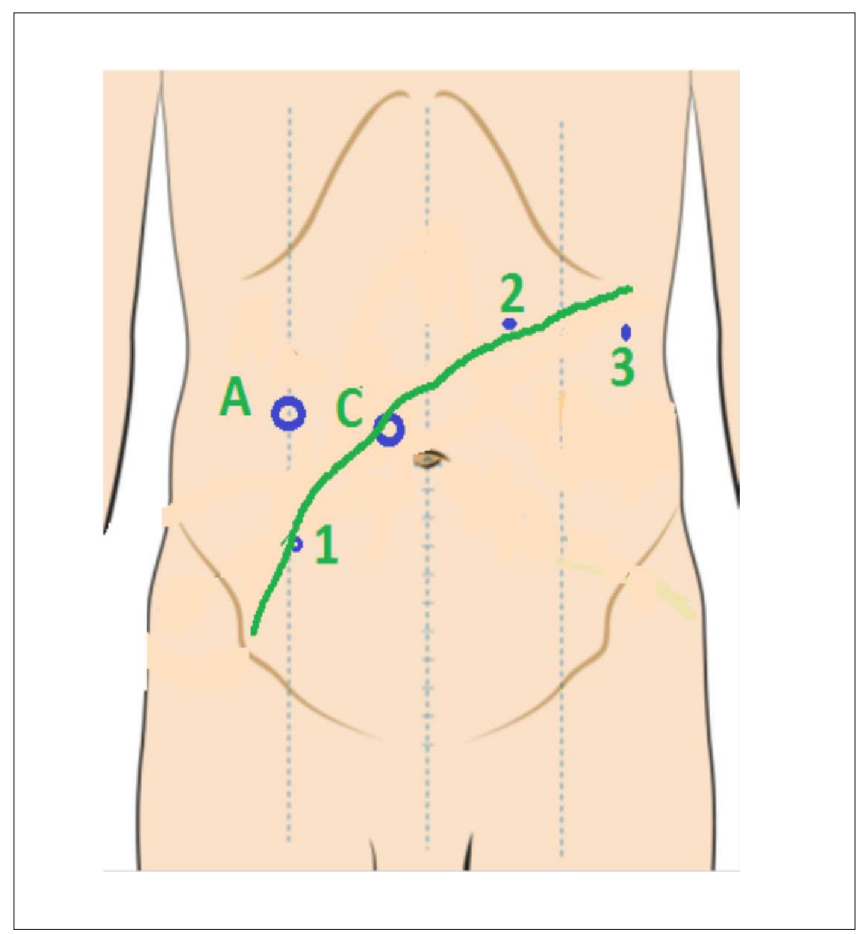

Figure 1 - Positioning of the trocars.

\section{4 - Mobilization of the left colon and splenic flexure by lateral access}

After right lateral traction of the sigmoid colon by the arm 3 grasper, the lateral release of the sigmoid colon and rectum begins by upper section of the peritoneum with the arm 1 monopolar scissors. Traction and counter traction performed with the arm 2 Cadiere forceps and the constant repositioning of the arm 3 clamp facilitate the exposure and identification of the left ureter and left spermatic or ovarian vessels. The section of the Toldt's fascia continues superiorly to the splenic flexure, with improved lateral and inferior traction of the distal descending colon provided by the arm 3 clamp. Colo-omental release of the greater omentum is done without the aid of the third arm to avoid external collisions, but with lower and right side traction of the distal transverse colon / splenic flexure, with an atraumatic grasper handled by the auxiliary. Sections and homeostasis of the omentum and of the phrenocolic and splenocolic ligaments are made with monopolar scissors and / or bipolar forceps with. The scissors can be replaced by robotic ultracision clamp (Figure 3).

\section{5 - Ligation of the inferior mesenteric} vessels by the medial approach

The operation begins with the incision of the peritoneum at the level of the promontory with the arm 1 scissors and follows from the right edge of the superior rectal artery until near the origin of the inferior mesenteric artery (IMA). Anterior traction and left side of the sigmoid colon by the third arm grasper holds the sigmoid mesocolon taut and facilitates the identification of the IMA. The arm 2 Cadiere helps in the exposure, dissection and antero-lateral traction of the IMA / superior rectal artery. The procedure continues in the space (window) between the superior rectal artery and aorta. This not only facilitates the identification, preservation and exhibition of the superior hypogastric (sympathetic) nerve plexuses but also of the left ureter. With changes in position of the arm 3 grasper, a precise

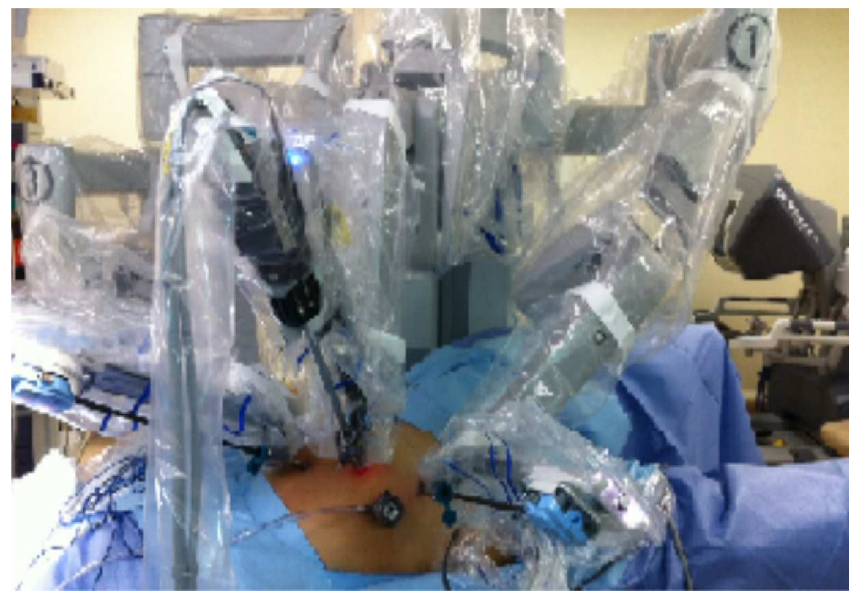

Figure 2 - Robot and tower in place. 
exposure of IMA is achieved. Two hemoloques are applied to the proximal portion of the IMA and one to the distal part by the robotic clip applier placed in the arm 1 instead of the scissors. After the ligation, section of IMA is carried out with the scissors replaced in arm 1. With anterior and left side traction of the sigmoid mesocolon by the arm 3 grasper, the inferior mesenteric vein (IMV) is then identified and dissected until the Toldt's fascia and clipped at the chosen location. In obese patients one can open a window in the sigmoid mesocolon, above the inferior mesenteric vessels, and reach the retroperitoneum already released by lateral access. The placement of the arm 3 grasper in this window statically lifts and pulls, the inferior mesenteric vessels and protects the retroperitoneal structures during dissection. In thin patients one can use the full mediallateral approach and monopolar hook in place of the scissors on the robotic arm 1 for hemostasis, dissection and section (Figure 4).

\section{6 - Total mesorectal excision, preservation of pelvic nerves and mobilization of the rectum}

The rectosigmoidectomy with a total mesorectal excision is performed in order to resect the visceral structures of the pelvis (rectum and mesorectum) covered by the visceral fascia and preserve the somatic structures (autonomic sympathetic and parasympathetic nerve plexuses), covered by the pelvic fascia. The total mesorectal excision and mobilization of the rectum are made according to the following systematization: 1- rectal dissection in the horizontal or sacral plane ${ }^{15,16}$ - the upper rectum is posteriorly dissected by section with scissors with monopolar cautery (arm 1) through the avascular presacral plane between the visceral and parietal fascia, with the promontorium as anatomical reference. The upper and right anterior traction of the rectosigmoid by the long grasper placed in the third robotic arm facilitates the exposure; this grasper remains motionless until further change of position. The anterior-superior traction of the mesorectum with the arm 2 bipolar fenestrated clamp enhances even more the exposure of the presacral space and the precise section of the avascular space and without nerve branches between the fascias (Angel's hair). With the same exposure, the right side peritoneum is transected, with the hypogastric nerves as anatomical reference. The arm 3 grasper is repositioned with opened blades and the rectum and mesorectum are risen anteriorly, allowing a safe dissection of the mesorectal space (Holly Plane) to the levator ani muscles laterally (end of the medium rectum), always with much precision, facilitated by the great exposure from traction provided by the arm 2 clamp and excellent vision offered by the 3DHD camera, with total stability and detailed enhancement of the anatomic structures; 2 - Lateral dissection of the rectum - there is the right side dissection, with section of the peritoneum with the arm 1 monopolar scissors, and steady and constant left-lateral traction afforded by the arm 3 long grasper.
The Cadiere forceps traction of the taut rectum to the left facilitates the precise section of the right lateral ligament and protects the right pelvic parasympathetic plexus (S2S3-S4). The superior right traction of the rectum by the arm 3 grasper is critical to the the left lateral dissection. At this time, the arm 2 Cadiere forceps is used to pull the left lateral ligament to the left, facilitating the section of the peritoneum and ligament with the arm 1 monopolar scissors. Sealing of the medium rectal vessels, when present (25\%), can be carried out with Cadiere forceps; 3 - dissection of the vertical, or pelvic, plane of the rectum - the dissection of the 4-6 cm distal rectum begins with exposure of the Waldeyer retossacral (fourth sacral vertebra) and reto-coccygeal ligaments, elevating the middle rectum with the arm 3 grasper and pulling the distal rectum anteriorly and inferiorly with the bipolar arm 2 Cadiere forceps. This exposure facilitates the section of

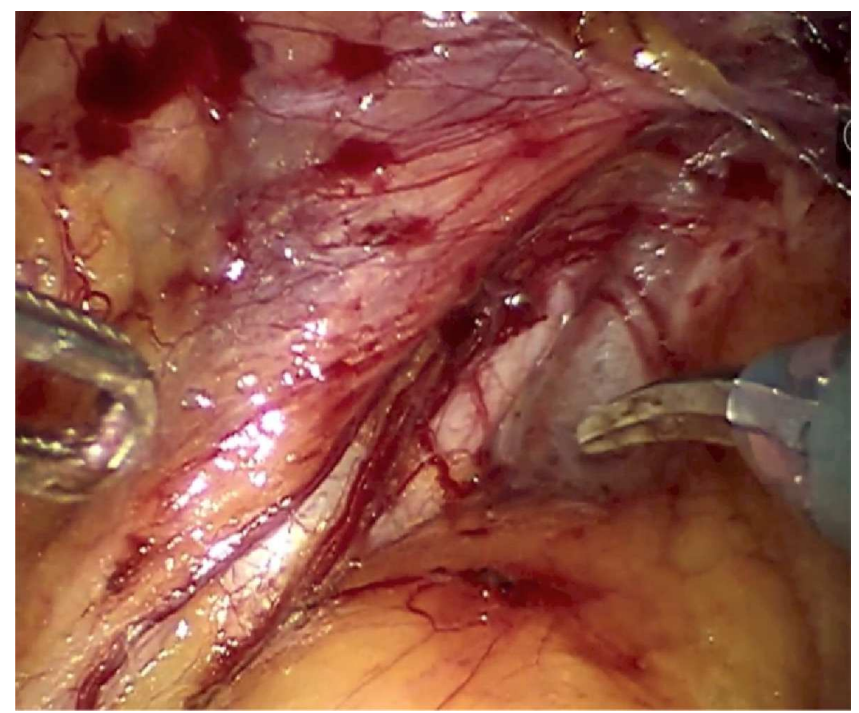

Figure 3 - Identification of the left ureter.

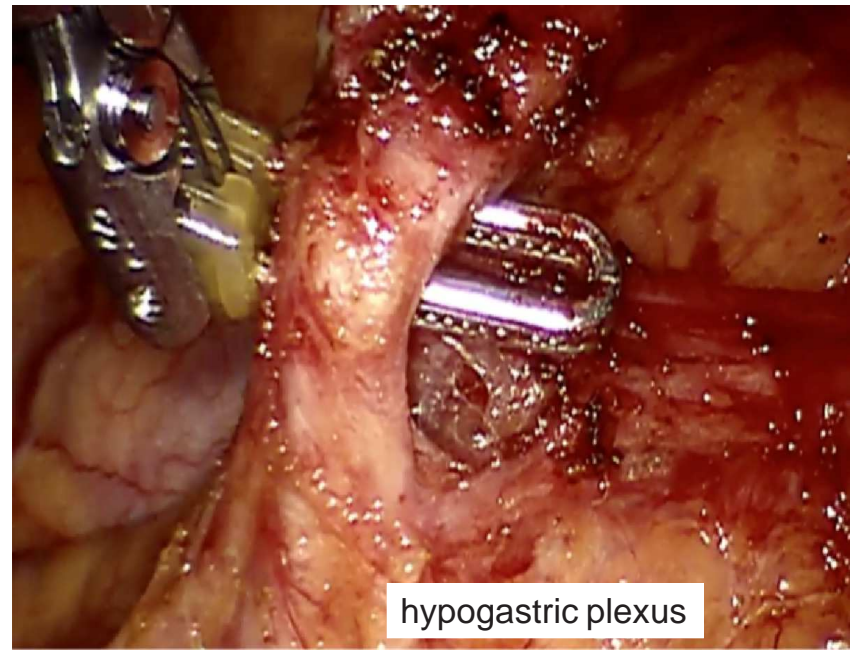

Figure 4 - Identification of the inferior mesenteric artery and preservation of the hypogastric plexus. 
the ligaments with the arm 1 monopolar scissors, which releases the rectum from the elevators, reaching the coccyx and the anal canal and keeping right and left pelvic plexus in of the postero-lateral wall of the pelvis intact (rhomboid structure of $2.5 \times 4 \mathrm{~cm}$ ). The superior right traction of the rectosigmoid with the auxiliary atraumatic laparoscopic forceps is crucial to improve the pelvic operative field. The anterior dissection terminates total mesorectal excision. The section of the anterior pelvic peritoneum is completed near the vaginal dome or seminal vesicles (Douglas pouch). The exhibition is made with superior traction of the rectosigmoid by the auxiliary atraumatic grasper and anterior traction of the bladder or vagina / uterus held by the arm 3 long grasper. The arm 2 bipolar Cadiere clamp controlled by the surgeon's left hand on the console exposes the field with superior and posterior traction of the rectum for the section with the scissors placed on arm 1 and controlled by the right surgeon's hand on the console. On all operative times the camera is adjusted by the surgeon to the necessary approximations for a magnificent view of the anatomic structures. The dissection progresses with small adjustments of the arm 3 grasper till the identification of the Denonvilliers retogenital fascia, which ought to be preserved in tumors located in the posterior wall of the rectum. The risk of injury to the nervi erigentes (parasympathetic) is greater when dissection is anterior to the fascia of Denonvilliers. In these cases the section of the fascia should be $U$ shaped (between 10 and 14h) to minimize the risk of injury to the nervi erigentes, to the Walsh neurovascular bundle, located near the side portion of the seminal vesicles, and preserving sexual and urinary functions (Fig. $5 \mathrm{a}, \mathrm{b}$ and c).

\section{7 - Section of distal rectum and coloanal or low colorectal anastomosis}

After the total liberation of the lower rectum, it is transected $2-3 \mathrm{~cm}$ below the tumor, using a cutting, linear, articulated endo-stapler with a $6 \mathrm{~cm}$ or $4.5 \mathrm{~cm}$ blue load, introduced by the auxiliary. The arm 3 grasper pulls the rectum superiorly and the arm 2 clamp tractions the vagina or prostate anteriorly. This exposure facilitates the placement of the endo-stapler on the top of the anal canal. Most often an additional stapling load is necessary to complete the section of the rectum. Next, the robot is undocked and a $5 \mathrm{~cm}$ transverse suprapubic incision is carried, with placement of an Alexis wound retractor. The rectum and sigmoid colon are removed and the proximal sigmoid colon is transected. The specimen is routed to the pathologist for assessment of the resection margins. The anvil of the circular stapler $(29-31 \mathrm{~mm})$ is connected to its male part, which is piercing the lateral wall of the sigmoid colon and the sigmoid section is staple with with a $6 \mathrm{~cm}$ blue load. The Alexis retractor is capped, and the pneumoperitoneum reestablished. The ultralow colorectal, or latero-terminal coloanal, anastomosis by double stapling is performed laparoscopically. The operation ends after testing the anastomotic integrity (Maneuver of the tire fitter), placement of a vacuum pelvic drain and lateral temporary ileostomy in selected cases.

\section{8 - Intersphincteric resection (IR) and manual latero-terminal coloanal anastomosis}

When the tumor is juxta-anal or intra-anal, partial or total intersphincteric resection is indicated by the perineal route. The robot is decoupled after the end of the vertical, or pelvic, dissection, and the leggings are repositioned for better exposure of the anal region. After closing of the anus with a 2-0 prolene running suture, a circumferential incision of the anal mucosa is carried out above, below or at the dentate line, depending on the distal edge of the tumor, comprising the internal sphincter wholly or partly. The surgery progresses to the intersphincteric dissection with electrocautery until the complete liberation of the anal canal reaches the robotic pelvic dissection at the posterior plane. The anterior and lateral release of the rectum is completed with the tumor and the specimen is retrieved transanally. The transection of the proximal sigmoid colon is made with a $7.5 \mathrm{~cm}$ cutting linear stapler and the manual
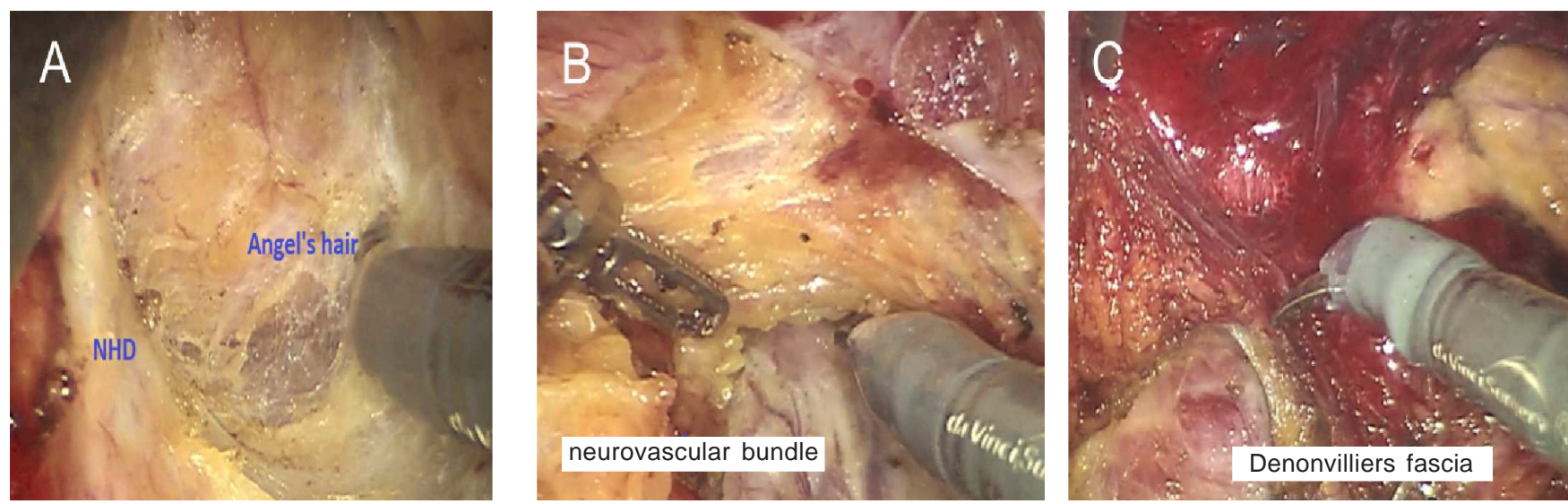

Figure 5 - Total mesorectal excision. a) dissection in the horizontal, or sacral, plane; b) lateral dissection; c) dissection in the vertical, or pelvic, plane. 
coloanal latero-terminal anastomosis is held in a single layer with 2-0 or 3-0 polyglactin sutures. The operation ends after pelvic drain placement, the performance of a lateral laparoscopic ileostomy and closure of the two puncture sites.

\section{9 - Extra-elevator, or cylindrical, abdominoperineal resection of the rectum with abdominal section of the levator ani muscles}

The extent of mesorectal excision in the rectal vertical,or pelvic, dissection phase depends on the tumor location given by the MRI (posterior, lateral, or anterior). In anterior tumors, the posterior dissection with section of the Waldeyer retossacral ligament is always performed. In posterior tumors, the robotic vertical dissection of the anterior rectum can be complete. The section of the elevator muscles is performed with robotic arm 1 monopolar scissors until the fat of the ischiorectal fossa after anterior traction of the distal rectum with the arm 3 grasper and exposure of the retossacral ligament and elevator muscles. The section of the muscles is made in a $\mathrm{U}$ fashion individually. The total cylindrical resection is indicated only for circumferential tumors. The coccygectomy is not routine. Once completed the robotics abdominal release, the robot is undocked and the leggings are repositioned to perform the perineal operation time in the lithotomy position. The extent of resection depends upon the degree of tumor invasion and tumor location. The posterior vaginal wall is resected in anterior tumors. Once completed the perineal resection, the cylindrical specimen is removed and the proximal sigmoid colon is transected with a linear stapler. When it is not possible to close the perineal incision, a rotation flap (gluteal muscle) is performed. The laparoscopic operation ends with the completion of the terminal colostomy, pelvic drain insertion, placement of the greater omentum in the pelvis and the pelvic peritoneum closure when possible (Figure 6 b).

\section{DISCUSSION}

One of the main advantages of the robotic system is the control by the surgeon of the stable 3DHD camera, which increases depth perception and promotes an optimum view of the operative field. The stable and magnified view allow precise identification of the hypogastric nerve plexus, and tremor filtration minimizes the risk of injury to anatomical structures during dissection. The various multi-articulated instruments $\left(180^{\circ}\right)$ high mobility of rotation $\left(540^{\circ}\right)$ allow the surgeon to perform complex movements and make a good exposure of the surgical field using the benefits of the third arm. Hemostasis can be meticulous and precise. In addition, in the robotic platform the surgeon is ambidextrous, and operates and comfortably seated in front of the console, with great ergonomics; physical stress is very small. The da Vinci system currently offers the articulated sealer (Vessel Sealer), the articulated endo-stapler (EndoWrist Stapler) and fluorescence imaging (Firefly) to evaluate perfusion of the lowered colon and rectal stump. Despite the robotic arms do not transmit tactile and tension sensations from tissues traction or sutures, the excellent vision is sufficient to prevent injuries to the noble structures (vessels, nerves, ureter, intestines), especially after overtaking the learning curve. The change in position of the patient and the undocking of the robot are inconvenient because they prolong the operative time by 5-10 minutes. However, the total cost of the robotic system and tools is still the main problem at the moment.

Basically three types of robotic techniques can be used for rectal cancer surgery. In the hybrid approach, the robot is used only to perform total mesorectal excision; the mobilization of the left colon and upper rectum and ligation of the inferior mesenteric vessels are performed laparoscopically. In the technique of multiple dockings, the robot can be docked / undocked two or three times. The devascularization, mobilization of the left colon and TME are made entirely robotic. In the technique of single
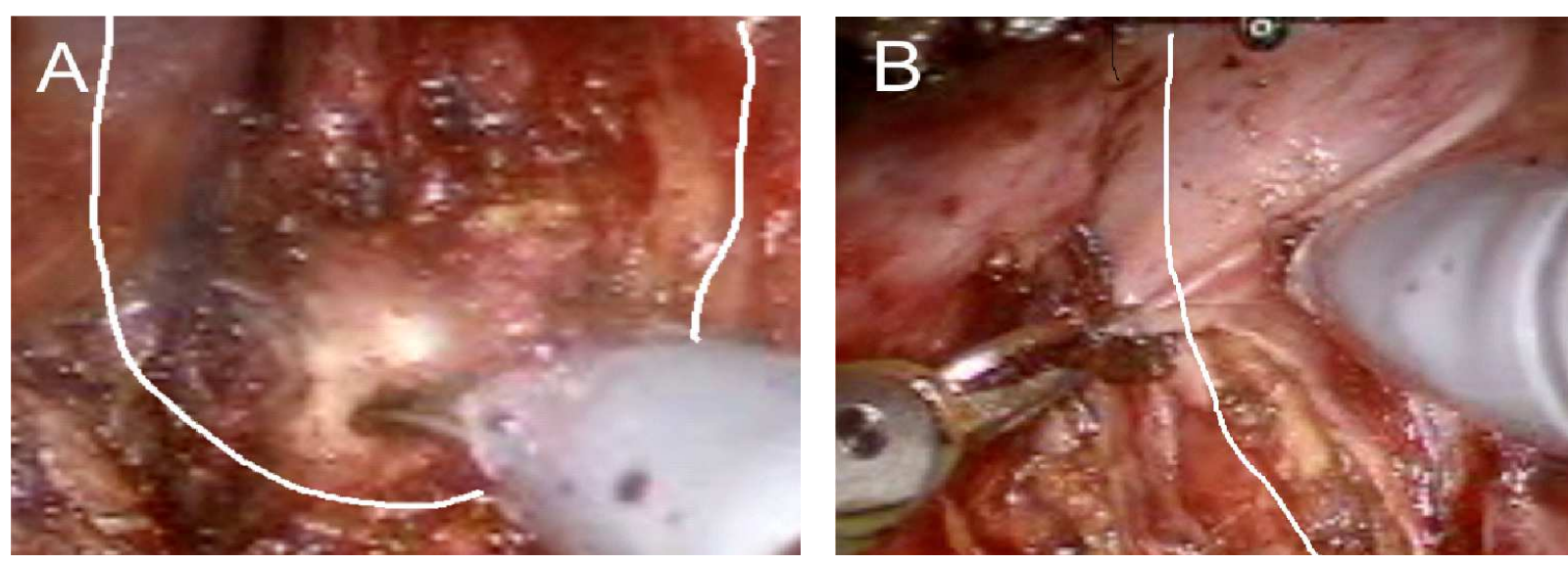

Figure 6 Cylindrical abdominoperineal resection of the rectum. a) and b) U-shaped abdominal section of the anus elevator muscles. 
undocking the operation is also performed entirely by the robot. The surgeon chooses one of the techniques according to his/her experience.

One of the main reasons for conversion of laparoscopic surgery in rectal cancer is the technical difficulty in pelvic dissection of tumors of the distal rectum in male, obese patients, and who have been treated with neoadjuvant QRT (conversion rate of 15-29\% 17,18 ). Therefore, the learning curve is long, and the number of patients needed, high (50 cases) ${ }^{19}$. There are articles ${ }^{20,21}$ reporting shorter learning curves in robotic surgery and a number of smaller patients to the surgeon acquire a high level of competence (15-25 cases) and lower rates of conversion of robotic surgery compared with laparoscopic resections in ultralow rectal resections (16.2 vs $2.1 \%$, $p=0.02) .{ }^{22,23}$ The conversion is directly related to the higher rate of postoperative complications (45\%) and mortality $(9 \%)^{18}$.

When using the robotic system, the precise dissection in the avascular space in the mesorretal excision (Holly plane) not only improves the quality of excision but also provides a greater number of surgical specimens with complete degree of excision, especially in ultralow anterior rectal resections ${ }^{24,25}$. In the CLASSIC study ${ }^{18}$ the circumferential resection margin (CRM) was positive in $12 \%$ of the laparoscopic group. Baik et al. Showed a significant difference $(p=0.033)$ in the rate of mesorretal excision when they compared robotics and laparoscopic low anterior resections ${ }^{26}$. Due to the great exposure and view of pelvic structures, the preservation of the nerves of the pelvic plexus is higher and hence the functional urinary and sexual results are better 27,28

Recent nonrandomized studies showed a higher incidence of anastomotic leak in anterior resections, especially in laparoscopically performed ultralow resections, the same incidence being lower in the robotic techniques $(13-15 \% \text { vs. } 3-6 \%)^{17,29,30}$.

Park et al. recently published an article evaluating the use of robotic surgery in totally abdominal intersphincteric resections in eight patients ${ }^{31}$. There was no conversion and the mean duration of surgery was 210 minutes. One complication (anastomotic leak) occurred and the distal and radial margins were negative in all cases.

The worst oncological outcomes of conventional abdominoperineal resection of the rectum may be related to a higher incidence of rectal or tumor perforation and positive circumferential margin found in surgical specimens. To minimize these results, Holm et al. proposed the extra-elevator APR (ELAPE), or cylindrical (CAPE), technique ${ }^{32}$, which is carried out with excision of the perineal elevators in supine position (jackknife position). In a review in 5,244 cases, Stelzner et al. showed a lower rate of positive CRM $(p=0.022)$ and perforation $(p=0.004)$ in the cylindrical resection group ${ }^{33}$. The local recurrence rate was significantly lower $(p<0.001)$. Marecik et al. prefer the lithotomy position, and abdominal robotic access for the section of the elevator muscles ${ }^{34}$. We prefer to individualize each operation and follow the guidance of Han et al., who recommend less extensive procedures according to the topography and size of the tumor and invasion of the elevator muscles, selected by pelvic magnetic resonance ${ }^{35}$, since the rates of perineal complications, mainly due to chronic pelvic pain and perineal hernia, are very high (> 50\%) and the closure of the perineal wound is more complex (rotation flaps, placement of meshes).

Currently, the indication of this new minimally invasive technology for the treatment of distal rectal cancer seems to benefit mainly male, obese patients, and who have been treated with preoperative chemoradiotherapy. The excellent quality of the mesorretal dissection, associated with excellent vision and pelvic surgical field exposure, may translate into lower rates of conversion and positive circumferential resection margin, and perhaps a lower incidence of anastomotic leak, even without conducting routine ileostomy.

We await with great interest the final results from the international, multicenter, randomized ROLARR study ${ }^{36}$ to evaluate the level of evidence and grade of recommendation of robotic surgery for the treatment of rectal cancer.

\section{R E S U M O}

Os autores apresentam, detalhadamente, as técnicas para o tratamento do câncer do reto distal utilizando o Sistema Robótico da Vinci S ${ }^{\circledR}$. São descritos os principais passos das operações: 1- Posição do Paciente; 2- Posicionamento dos trocartes e do robô; 3 Mobilização do cólon sigmoide, cólon descendente e ângulo esplênico pelo acesso látero-medial; 4- Ligadura dos vasos mesentéricos inferiores pelo acesso medial; 5- Excisão total do mesorreto, preservação dos nervos pélvicos (dissecção horizontal ou sacral, dissecção lateral e dissecção vertical ou pélvica); 6- Secção do reto distal com o endogrampeador e anastomose coloanal (Tumor tipo 1); 7- Ressecção interesfinctérica, extração da peça pelo ânus e anastomose látero-terminal manual (Tumor tipo II); 8- Ressecção abdominoperineal do reto cilíndrica com secção dos músculos elevadores do ânus por via abdominal (Tumor tipo IV). A utilização dessas técnicas, apesar de serem complexas, mostrou-se segura, com baixo índice de complicação pós-operatória e sem mortalidade.

Descritores: Neoplasias retais. Tratamento. Cirurgia. Técnicas. Robótica. 


\section{REFERENCES}

1. Miles EW. A method of performing abdominoperineal excision for carcinoma of the rectum and of the terminal portion of the pelvic column. Lancet. 1908;2:1812-3.

2. MacFarlane JK, Ryall RD, Heald RJ. Mesorectal excision for rectal cancer. Lancet. 1993;341(8843):457-60.

3. Habr-Gama A, Sabbaga J, Gama-Rodrigues J, São Julião GP, Proscurshim I, Bailão Aguilar P, et al. Watch and wait approach following extended neoadjuvant chemoradiation for distal rectal cancer: are we getting closer to anal cancer management? Dis Colon Rectum. 2013;56(10):1109-17.

4. Nougaret S, Reinhold C, Mikhael HW, Rouanet P, Bibeau F, Brown $G$. The use of MR imaging in treatment planning for patients with rectal carcinoma: have you checked the "DISTANCE"? Radiology. 2013:268(2):330-44.

5. Rullier E, Denost $Q$, Vendrely $V$, Rullier A, Laurent C. Low rectal cancer: classification and standardization of surgery. Dis Colon Rectum. 2013;56(5):560-7.

6. Han JG, Wang ZJ, Wei GH, Gao ZG, Yang Y, Yi BQ, et al. Technical improvements and results of individual cylindrical abdominoperineal resection for locally advanced low rectal cancer. Zhonghua Wai Ke Za Zhi. 2013;51(4):335-8.

7. Jayne DG, Thorpe HC, Copeland J, Quirke P, Brown JM, Guillou PJ. Five-year follow-up of the Medical Research Council CLASICC trial of laparoscopically assisted versus open surgery for colorectal cancer. Br J Surg. 2010;97(11):1638-45

8. Kang SB, Park JW, Jeong SY, Nam BH, Choi HS, Kim DW, et al. Open versus laparoscopic surgery for mid or low rectal cancer after neoadjuvant chemoradiotherapy (COREAN trial): short-term outcomes of an open-label randomised controlled trial. Lancet Oncol. 2010;11(7):637-45.

9. van der Pas MH, Haglind E. Cuesta MA. Fürst A, Lacy AM, Hop WC, et al. Laparoscopic versus open surgery for rectal cancer (COLOR II): short-term outcomes of a randomised, phase 3 trial. Lancet Oncol. 2013;14(3):210-8.

10. Greenblatt DY, Rajamanickam V, Pugely AJ, Heise CP, Foley EF, Kennedy GD. Short-term outcomes after laparoscopic-assisted proctectomy for rectal cancer: results from the ACS NSQIP. Am Coll Surg. 2011;212(5):844-54.

11. Arezzo A, Passera R, Scozzari G, Verra M, Morino M. Laparoscopy for rectal cancer reduces short-term mortality and mormidity: results of a systematic review and meta-analysis. Surg Endosc. 2013;27(5):1485-502

12. Ramos JR, Petrosemolo RH, Valory EA, Polania FC, Peçanha R. Abdominoperineal resection: laparoscopic versus conventional. Laparosc Endosc. 1997;7(2):148-52.

13. Halabi WJ, Kang CY, Jafari MD, Nguyen VQ, Camichael JC, Mills S, et al. Robotic-assisted colorectal surgery in the United States: a nationwide analysis of trends and outcomes. World J Surg. 2013;37(12):2782-90.

14. Zang $Y$, Wang F, Zhang P, Sou Y, Qin H, Ma Y. Robotic-assisteded versus conventional laparoscopic surgery for colorectal disease, focusing on rectal cancer: a meta-analysis. Ann Surg Oncol. 2012;19(12):3727-36.

15. Ramos JR. Ressecção anterior ultrabaixa e interesfinctérica do reto com anastomose coloanal por videolaparoscopia. Rev Col Bras Cir. 2009;36(5):459-65.

16. Koh PK, Seow-Choen F, Kwek BH. Total mesorectal excision: the unrecognized pelvic plane. Dis Colon Rectum. 2006;49(2):280-3; discussion 283-4.

17. Rottoli M, Bona S, Rosati R, Elmore U, Bianchi PP, Spinelli A, et al. Laparoscopic rectal resection for cancer: effects of conversion on short-term outcome and survival. Ann Surg Oncol. 2009;16(5):1279-86.

18. Guillou PJ, Quirke P, Thorpe H, Walker J, Jayne DG, Smith AM, et al. Short-term endpoints of conventional versus laparoscopicassisted surgery in patients with colorectal cancer (MRC CLASICC trial): multicentre, randomised controlled trial. Lancet. 2005;365(9472):1718-26

19. Kayano H, Okuda J, Tanaka K, Kondo K, Tanigawa N. Evaluation of the learning curve in laparoscopic low anterior resection for rectal cancer. Surg Endosc. 2011;25(9):2972-9.

20. Bokhari MB, Patel CB, Ramos-Valadez DI, Ragupathi M, Haas EM. Learning curve for robotic-assisted laparoscopic colorectal surgery. Surg Endosc. 2011;25(3):855-60.

21. Jiménez-Rodríguez RM, Díaz-Pavón JM, de la Portilla de Juan F, Prendes-Sillero E, Dussort HC, Padillo J. Learning curve for roboticassisted laparoscopic rectal cancer surgery. Int J Colorectal Dis. 2013:28(6):815-21.

22. Baek SJ, Al-Asari S, Jeong DH, Hur H, Min BS, Baik SH, et al. Robotic versus laparoscopic coloanal anastomosis with or without intersphincteric resection for rectal cancer. Surg Endosc. 2013;27(11):4157-63.

23. Yang $Y$, Wang $F$, Zhang $P$, Shi $C$, Zou $Y$, Qin $H$, et al. Robotassisted versus conventional laparoscopic surgery for colorectal disease, focusing on rectal cancer: a meta-analysis. Ann Surg Oncol. 2012;19(12):3727-36

24. Baik SH, Kim NK, Lim DR, Hur H, Min BS, Lee KY. Oncologic outcomes and perioperative clinicopathologic results after robotic-assisted tumor-specific mesorectal excision for rectal cancer. Ann Surg Oncol. 2013;28(8):2625-32.

25. Kang J, Yoon KJ, Min BS, Hur H, Baik SH, Kim NK, et al. The impact of robotic surgery for mid and low rectal cancer: a case-matched analysis of a 3-arm comparison-open, laparoscopic, and robotic surgery. Ann Surg. 2013;257(1)95-101.

26. Baik SH, Kwon HY, Kim JS, Hur H, Sohn SK, Cho CH, et al. Robotic versus laparoscopic low anterior resection of rectal cancer: shortterm outcome of a prospective comparative study. Ann Surg Oncol. 2009;16(6):1480-7.

27. Luca F, Valvo M, Ghezzi TL, Zuccaro M, Cenciarelli S, Trovato C, et al. Impact of robotic surgery on sexual and urinary functions after fully robotic nerve-sparing total mesorectal excision for rectal cancer. Ann Surg. 2013;257(4):672-8

28. D'Annibale A, Pernazza G, Monsellato I, Pende V, Lucandri G, Mazzocchi $P$, et al. Total mesorectal excision: a comparison of oncological and functional outcomes between robotic and laparoscopic surgery for rectal cancer. Surg Endosc. 2013;27(6):1887-95

29. Zeng DZ, Shi Y, Lei X, Tang B, Hao YX, Luo HX, et al. Short-term efficacy of da Vinci robotic surgical system on rectal cancer in 101 patients. Zhonghua Wei Chang Wai Ke Za Zhi. 2013;16(5):451-4.

30. deSouza AL, Prasad LM, Marecik SJ, Blumetti J, Park JJ, Zimmern A, et al. Total mesorectal excision for rectal cancer: the potential advantage of robotic assistance. Dis Colon Rectum. 2010;53(12):1611-7.

31. Park SY, Choi GS, Park JS, Kim HJ, Choi WH, Ryuk JP. Roboticassisted transabdominal intersphincteric resection: a technique involving a completely abdominal approach and coloanal anastomosis. Surg Laparosc Endosc Percutan Tech. 2013;23(1):e510.

32. Stelzner S, Koehler C, Stelzner J, Sims A, Witzigmann H. Extended abdominoperineal excision versus standard abdominoperineal excision in rectal cancer-a systematic overview. Int J Colorectal Dis. 2011;26(10):1227-40.

33. Holm T, Ljung A, Haggmark T, Jurell G, Lagergren J. Extended abdominoperineal resection with gluteos maximus flap reconstruction of the pelvic floor for rectal cancer. Br J Surg. 2007;94(2):232-8

34. Marecik SJ, Zawadzki M, Desouza AL, Park JJ, Abcarian H, Prasad LM. Robotic cylindrical abdominoperineal resection with transabdominal levator transection. Dis Colon Rectum. 2011;54(10):1320-5.

35. Han JG, Wang ZJ, Wei GH, Gao ZG, Yang Y, Zhao BC. Randomized clinical trial of conventional versus cylindrical abdominoperineal resection for locally advanced lower rectal cancer. Am J Surg. 2012;204(3):274-82. 
36. Collinson FJ, Jayne DG, Pigazzi A, Tsang C, Barrie JM, Edlin R, et al. An international, multicentre, prospective, randomised, controlled, unblinded, parallel-group trial of robotic-assisted versus standard laparoscopic surgery for the curative treatment of rectal cancer. Int J Colorectal Dis. 2012;27(2):233-41.
Received on 15/08/2013

Accepted for publication 18/10/2013

Conflict of interest: none.

Source of funding: none.

Address for correspondence:

José Reinan Ramos

E-mail: jreinanramos@hotmail.com 